Research Journal of Applied Sciences 13 (10): 587-593, 2018

ISSN: $1815-932 \mathrm{X}$

(C) Medwell Journals, 2018

\title{
A Risk Simulation of Rice Blast Disease under Combining Between Atmosphere and Soil Conditions
}

\author{
${ }^{1,4}$ Sarinya Kirtphaiboon, ${ }^{2}$ Usa Humphries, ${ }^{3}$ Thidarat Bunsri and ${ }^{1,4}$ Prungchan Wongwises \\ ${ }^{1}$ The Joint Graduate School of Energy and Environment, \\ ${ }^{2}$ Department of Mathematics, Faculty of Sciences, \\ ${ }^{3}$ Center of Excellence on Hazardous Substance Management, \\ Department of Environmental Engineering, Faculty of Engineering, \\ King Mongkut's University of Technology Thonburi, Thonburi, Thailand \\ ${ }^{4}$ Center of Excellence on Energy Technology and Environment, Perdo, Bangkok, Thailand
}

\begin{abstract}
Rice blast disease leads to a decrease in the yield of rice in Thailand. The severity of the disease in certain production situations is exacerbated by the environmental conditions and crop-management practices. Climate change is a direct threat to agriculture which is impacted by high temperatures, drought and flood. This research aims to simulate the risk of rice blast disease under the climate changing combined between the atmosphere and soil module, investigating the atmosphere and soil variables, air temperature, relative humidity, soil temperature and rainfall. The variables are collected in ten realistic bed experiments in Prachin Buri Province, Thailand which were planted each month between July 2015 and May 2016. The study found that rice blast disease develops under conditions where air temperature is $25-29^{\circ} \mathrm{C}$, relative humidity $60-80 \%$ and soil temperature $28-31^{\circ} \mathrm{C}$ which leads to the germination and sporulation of fungus. This research is simulated that the suitable climate conditions of the rice blast disease outbreak under combining the atmosphere and soil conditions in Prachin Buri Province is between December 2015 and March 2016.
\end{abstract}

Key words: Risk simulation, rice blast disease, severity, atmosphere and soil conditions, production, temperature

\section{INTRODUCTION}

In Thailand, rice is an economic crop and a staple food. Approximately $55 \%$ of the rice produced is consumed domestically and the remaining $45 \%$ is exported (Anonymous, 2005). Khao Dawk Mali 105 is a major rice product which brings income to the country. Domestic consumption of rice is expected to rise over the next 20 years by about $20-30 \%$ due to an increasing population and rice-producing capacity (Anonymous, 2005). The major problem effecting rice production is insects and the outbreak of diseases, especially rice blast disease. Rice blast disease occurred in the North and Northeast of Thailand in 1992, causing a reduction in rice production of 650,000 tons and a loss of 3,000 million baht (Disthaporn, 1994). Rice blast is one of the most problematic diseases in the rice-growing areas around the world including Thailand (Disthaporn, 1994; Saka, 2006). The sexual form (Magnaporthe grisea Barr.) of the fungus predominantly occurs in temperate environments while the asexual form (Pyricularia oryzae; $P$. oryzae) occurs in tropical environments (Ou, 1980). The severity of the disease is exacerbated by the environmental conditions and crop management practices (Teng and Yuen, 1991).

The rice cycle of the rice blast fungus begins when the conidia produced on lesions is disseminated and comes into contact with the rice leaf surface. The production phase and the release and dissemination phase both occur at $92-96 \%$ of relative humidity. Peak spore production occurs during the night when the relative humidity is high $100 \%$ and the temperature is approximately $22^{\circ} \mathrm{C}$ (Bevitori and Ghini, 2014). To penetrate a leaf, the spore attaches to the hydrophobic cuticle and germinates under the wet environmental conditions. The conidia start with small tube germination after 30-90 min and the onset of infection is highly dependent on water. Appressorium formation occurs, on average, at $24-28^{\circ} \mathrm{C}$. Fungal penetration requires a minimum of 6-8 $\mathrm{h}$ of wetness and occurs at an optimal temperature of $25^{\circ} \mathrm{C}$. Sporulation then begins on wounds when the relative humidity is at least $93 \%$.

Corresponding Author: Usa Humphries, Department of Mathematics, King Mongkut's University of Technology Thonburi, 126 Pracha Uthit Roadd., Bangmod, Thung Khru, 10140 Bangkok, Thailand 
Rapid growth of lesions is favoured by alternating temperatures of $25 / 32$ and $20 / 32^{\circ} \mathrm{C}$. Disease lesions occur between 72 and $96 \mathrm{~h}$ after infection and sporulation occurs under humid conditions. After 144 $\mathrm{h}$ of high humidity, the lesions begin to produce spores (Howard, 1994; Dean et al., 2005). The most important climatic factors are temperature and relative humidity. These factors may be modified by the impact of future climate change (Howard, 1994; Dean et al., 2005; Prabhu et al., 2008). Many researchers have developed models of rice blast disease such as the regression and dynamic models. For example, the impact of climate conditions on the severity of the disease was evaluated (Calvero et al., 1996; Kaundal et al., 2006) and studied at different stages of the disease cycle (Kim et al., 1987). The model of pathogenic fungi has also, been merged with the plant model to define the effect of blast disease on photosynthesis and yield under climate change (Luo et al., 1997, 1998). Moreover, they were applied to generate the global risk maps of the potential epidemics (Savary et al., 2012; Kim et al., 2015).

This research aims to simulate the risk of rice blast disease under the climate changing combined between the atmosphere and soil conditions. In this case study, the realistic beds are demonstrated in the Prachin Buri Rice Research Center using the climatic variables of air temperature, relative humidity, soil temperature and rainfall.

\section{MATERIALS AND METHODS}

Research data: This research planted ten beds for rice planting each month between November 2015 and August 2016 in the Prachin Buri Rice Research Center, Prachin Buri Province, Thailand as shown in Table 1. Each bed had a width of $9 \mathrm{~m}$, a length of $21.5 \mathrm{~m}$ and an area of $193.5 \mathrm{~m}^{2}$. These beds were corrected for the daily climate data such as air temperature, relative humidity, soil temperature and rainfall.

Risk score: A risk score of the rice blast disease is studied using the probability theory which is a branch of mathematics that calculates the likelihood of a given event happening. The risk score of rice blast disease is considered using the climate variables of air temperature, relative humidity and soil temperature. They are classified on the rating curve of rice blast disease depending on their change. It is written as:

$$
R_{x i}=\frac{\left(F_{j} \times S\right) x_{i}}{\left(F_{t}\right) x_{i}}
$$

Where:

$\mathrm{R}_{\mathrm{xi}}=$ The risk score of the environment variable

$\mathrm{x}_{\mathrm{i}}=$ As air temperature (a), relative humidity (h) and soil temperature $(s)$

$F_{j}=$ The number of individuals of rice blast disease outbreak at an intensity interval $\mathrm{j}$

$\mathrm{F}_{\mathrm{t}}=$ The total number of individuals of rice blast disease outbreak from all intensity intervals

$\mathrm{S}=$ The severity of rice blast disease

Risk index: To describe the effects of host aging and weather variables on the host-pathogen interaction, the effects of air temperature, relative humidity and soil temperature were incorporated into the model. The risk index can be calculated as:

$$
\text { Riskindex }=\prod_{\mathrm{i}=1}^{\mathrm{n}}\left(\mathrm{R}_{\mathrm{xi}}\right)^{\frac{1}{\mathrm{n}}}
$$

where, $\mathrm{R}_{\mathrm{xi}}$ is the risk score of the environment variable $\mathrm{x}_{\mathrm{i}}$; as air temperature $\left(\mathrm{x}_{\mathrm{a}}\right)$, soil temperature $\left(\mathrm{x}_{\mathrm{s}}\right)$ and relative humidity is the number of the collected variable $i$ and $\left(x_{h}\right)$ that $\mathrm{i}=1,2,3, \ldots, \mathrm{n}$.

Risk classification: A Gompertz function is a time series mathematical model where growth is slowest at the start and end of a time period and has been shown to be useful for studies of animal populations (Gompertz, 1825). It has also, been used to summarise disease progression and is a good fit for the study of the rice blast pathosystem (Mohapatra et al., 2008).

\begin{tabular}{lll} 
Table 1: Rice planting in the Prachin Buri Rice Research Center & \\
\hline Bed & Date of rice planting & Date of rice blast disease outbreak \\
\hline 1 & 28 July 2015-25 November 2015 & 16 August 2015-2 October 2015 \\
2 & 1 September 2015-14 December 2015 & - \\
3 & 27 September 2015-24 December 2015 & - \\
4 & 31 October 2015-25 January 2016 & - \\
5 & 29 November 2015-31 March 2016 & 23 December 2015-23 March 2016 \\
6 & 25 December 2015-22 April 2016 & 16 January 2016-11 March 2016 \\
7 & 30 January 2016-1 June 2016 & 2 March 2016-26 March 2016 \\
8 & 28 February 2016-30 June 2016 & 26 March 2016-30 June 2016 \\
9 & 6 April 2016-30 July 2016 & 9 June 2016-30 July 2016 \\
10 & 1 May 2016-28 August 2016 & 23 June 2016-20 August 2016 \\
\hline
\end{tabular}


This research fitted the classification risk curve of rice blast disease using the Gompertz equation:

$$
y=A e^{-b e^{-c t}}
$$

where $\mathrm{A}$ is the carrying capacity, $\mathrm{b}$ is the displacement along the $\mathrm{x}$-axis, $\mathrm{c}$ is the growth rate, $\mathrm{e}$ is Euler 's number $(\mathrm{e}=2.71828)$ and $\mathrm{t}$ is time.

\section{RESULTS AND DISSCUSSION}

Risk score of climatic variables: The climatic variables most suitable for the rice blast disease are air temperature between $25-29^{\circ} \mathrm{C}$, relative humidity between $60-80 \%$ and soil temperature between $28-31^{\circ} \mathrm{C}$. The maximum on the rating curve for air temperature, relative humidity and soil temperature are $27,70 \%$ and $29^{\circ} \mathrm{C}$, respectively as shown in Fig. 1.

Risk simulation of rice blast disease: The rice blast disease experiment in the Prachin Buri Rice Research Center was scored by measuring the size of the lesion on the rice leaf and evaluating the risk of rice blast disease. The assessment of the severity of the rice blast disease identified that the fungus (P.oryzae) grows well when the air temperature is quite cold to warm and the relative humidity is quite high. In other climate conditions the fungus is in the filamentous phrase and it cannot produce the spore. The outbreak of the rice blast disease in the bed experiment is shown in Fig. 2.

The bed experiment identified outbreaks of rice blast disease in the $1 \mathrm{st}, 5$ th-10th beds. The severity of rice blast disease in the 1 st bed was very severe (1.00) at two stages: at 26-28 days and 78-91 days after planting and at 108-118 days after planting in the heading stage as shown in Fig. 3a. The model captured some parts of the outbreak of rice blast disease. The decaying cause of rice blast disease assumes that P.oryzae is inhibited by rain so it cannot transplant to the healthy rice leaf. The average air temperature, soil temperature, relative humidity and rainfall was $27.2,28.8^{\circ} \mathrm{C}, 81.8 \%$ and $6.5 \mathrm{~mm} /$ day, respectively.

The severity of rice blast disease in the 5 th bed was very severe (1.00) in two stages: during 2-7 days after planting in the seedling stage and with germination of the
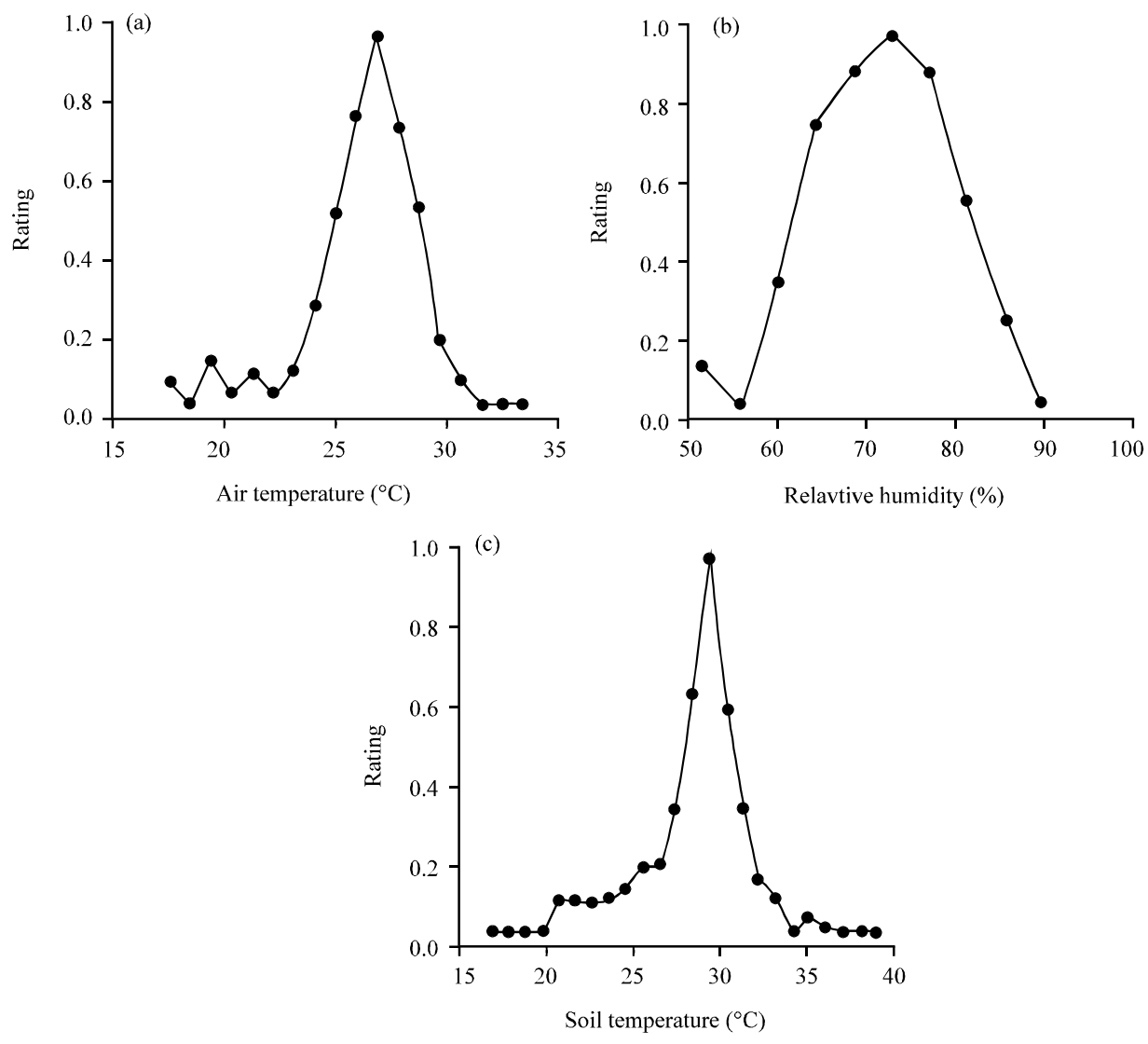

Fig. 1: Rating curve of the rice blast disease; a) Air temperature; b) Relative humidity; c) Soil temperature 
Res. J. Applied Sci., 13 (10): 587-593, 2018



Fig. 2: Outbreak of the rice blast disease in the bed experiment

leaf and at 63-124 days after planting in the tillering and heading stages as shown in Fig. 3b. The average air temperature, soil temperature, relative humidity and rainfall was $26.5^{\circ} \mathrm{C}, 27.5^{\circ} \mathrm{C}, 71.6 \%$ and $0.2 \mathrm{~mm} /$ day, respectively. The model captured some parts of the outbreak of rice blast disease.

The severity of rice blast disease in the 6 th bed was very severe (1.00) in two stages: at 51-62 days after planting in the tillering stage and during 93-102 days after planting in the heading stage as shown in Fig. 3c. In particular, the weather between December and February was cool with low relative humidity which establishes suitable conditions for infection of rice blast disease while in March the low rainfall inhibited the growth of P.oryzae. The average air temperature, soil temperature, relative humidity and rainfall was $27.2^{\circ} \mathrm{C}, 28.2^{\circ} \mathrm{C}, 70.8 \%$ and 0.1 $\mathrm{mm} /$ day, respectively.

The severity of rice blast disease in the 7 th bed was very severe (1.00) in two stages: at 15-26 days after planting in the seedling stage and at 57-66 days after planting in the tillering stage as shown in Fig. 3d. The weather during January and February was cool with low relative humidity which established suitable conditions for the infection of rice blast disease. The low rainfall that followed in March inhibited the development of $P$. oryzae. The average air temperature, soil temperature, relative humidity and rainfall was 28.4 and $30^{\circ} \mathrm{C}, 70 \%$ and $1.3 \mathrm{~mm} /$ day, respectively. The severity of rice blast disease in the 8 th bed was very severe $(1.00)$ in the seedling stage: at 6-12 and 28-37 days after planting as shown in Fig. 3e. The weather conditions were not suitable for $P$. oryzae from April onwards. The average air temperature, soil temperature, relative humidity and rainfall was $28.7^{\circ} \mathrm{C}$ and $30.9^{\circ} \mathrm{C}, 73.5 \%$ and $2.6 \mathrm{~mm} /$ day, respectively.

The severity of rice blast disease in the 9th bed was very severe (1.00) in the tillering and heading stages: 64 ,
$74,90,113$ and 114 days after planting as shown in Fig. 3f. The rice blast disease in this bed was not continuous but the weather conditions in July were found to be suitable for infection of $P$. oryzae. The average air temperature, soil temperature, relative humidity and rainfall was $28.4^{\circ} \mathrm{C}$, $31.1^{\circ} \mathrm{C}, 77.1 \%$ and $4.9 \mathrm{~mm} /$ day, respectively. The severity of rice blast disease in the 10th bed was very severe (1.00) in the tillering and heading stages: 65, 88, 89, 94 and 117 days after planting as shown in Fig. 3g. The rice blast disease in this bed was not continuous but the weather conditions during July and August were suitable for infection of $P$. oryzae. The average air temperature, soil temperature, relative humidity and rainfall was $27.7^{\circ} \mathrm{C}$ and $32.6^{\circ} \mathrm{C}, 79.3 \%$ and $6.1 \mathrm{~mm} /$ day, respectively.

The method of risk simulation was used for considering the probability of disease severity under the suitable weather factors. This study investigated the risk score, risk index and severity of the rice blast disease under combining between the atmosphere and soil conditions. In general, the rice blast disease caused by $P$. oryzae in anamorph stage and Magnaporthe grisea in telomorph stage (Rossman, 1990). The infection and sporulation of fungus were under cool and high humid conditions (Howard, 1994). Moreover, Iram et al. (2003) found that the fungus that can spread in soil, caused the disease in rice stalk and root as blast, root rot, brown spot and bacterial leaf streak. In addition, Kumar et al. (1998) found that the fungus can spread both of soil and seed borne. The sporulation requires the night time dew. Then, this study is considered the weather variables as air temperature, relative humidity and soil temperature that are the important factor for sporulation of fungus. It found that the risk score of the weather variables of air temperature, relative humidity and soil temperature correspond to the suitable conditions for the outbreak of rice blast disease: air temperature of $25-27^{\circ} \mathrm{C}$, relative humidity of $60-80 \%$ and soil temperature of $28-31^{\circ} \mathrm{C}$. 
Res. J. Applied Sci., 13 (10): 587-593, 2018
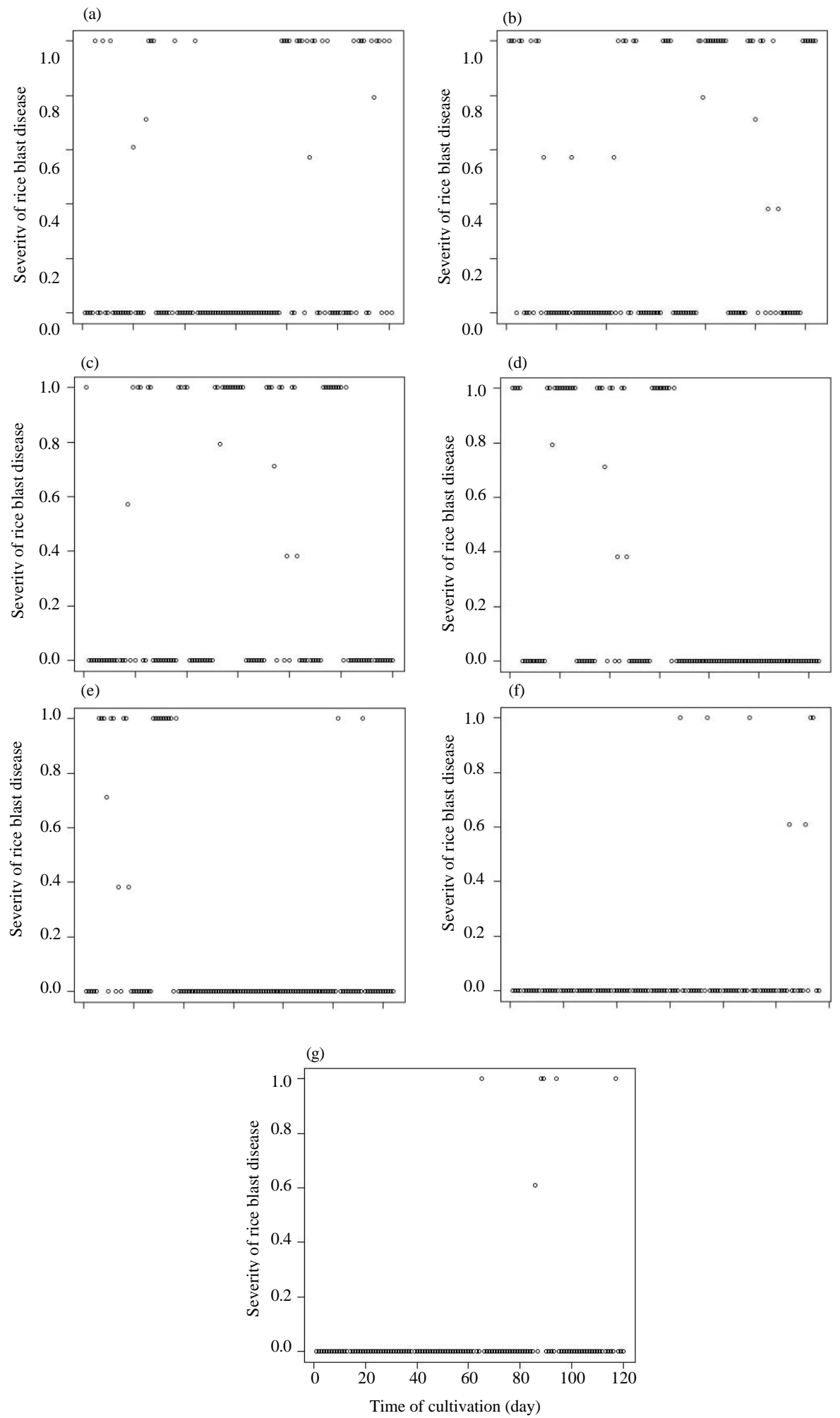

Fig. 3: Severity of rice blast disease in the bed experiment: a) Severity of rice blast disease in the first bed; b) Severity of rice blast disease in the fifth bed; c) Severity of rice blast disease in the sixth bed; d) Severity of rice blast disease in the seventh bed; e) Severity of rice blast disease in the eighth bed; f) Severity of rice blast disease in the ninth bed and g) Severity of rice blast disease in the tenth bed 
Especially, the analysis of the maximum risk scores for air temperature, relative humidity and soil temperature are peak disease severity in $27^{\circ} \mathrm{C}, 70 \%$ and $29^{\circ} \mathrm{C}$, respectively.

\section{CONCLUSION}

To consider the disease severity of each month, it found that the suitable climate conditions between December 2015 and March 2016 were shown to be a decrease in air and soil temperatures but an increase in relative humidity. Moreover, the rice received excessive water due to high rainfall between May and August 2016 which inhibited the infection of $P$. oryzae. However, the classification of disease should take into consideration when it is infected as demonstrated in the case of the non-continuous disease that $P$. oryzae can be active or inhibited.

\section{ACKNOWLEDGEMENTS}

The researcher acknowledge the Prachin Buri Rice Research Center for the experiment of the realistic bed. This study was also supported by the Thailand Research Fund through the International Research Network [grant number IRN5701PDW0001], the Joint Graduate School of Energy and Environment (JGSEE), the Centre of Excellence on Energy technology and environment (CEE) and Science and Technology Postgraduate Education, Research Development Office (PERDO).

\section{REFERENCES}

Anonymous, 2005. Thai rice exporters association. Nfi Training and Food Intelligence Center, Bangkok, Thailand. http://fic.nfi.or.th foodsectordatabankdetail.php?id=9

Bevitori, R. and R. Ghini, 2014. Rice blast disease in climate change times. Rice Res. Open Access, 3: 1-2.

Calvero, J.S.B., S.M. Coakley and P.S. Teng, 1996. Development of empirical forecasting models for rice blast based on weather factors. Plant Pathol., 45: 667-678.

Dean, R.A., N.J. Talbot, D.J. Ebbole, M.L. Farman and T.K. Mitchell et al., 2005. The genome sequence of the rice blast fungus Magnaporthe grisea. Nat., 434: 980-986.

Disthaporn, S., 1994. Current Rice Blast Epidemics and their Management in Thailand. In: Rice Blast Disease, Zeigler, R.S., S.A. Leong and P.S. Teng (Eds.). International Rice Research Institute, Los Banos, Philippines, pp: 321-332.
Gompertz, B., 1825. On the nature of the function expressive of the law of human mortality and on a new mode of determining the value of life contingencies. Philos. Trans. R. Soc. London, 115: 513-585.

Howard, R.J., 1994. Cell Biology of Pathogenesis. In: Rice Blast Disease, Zeigler, R.S., S.A. Leongand P.S. Teng (Eds.). International Rice Research Institute, Los Banos, Philippines, pp: 3-22.

Iram, S., A. Iftikhar and M. Ashraf, 2003. A study on fungi and soil born diseases associated with rice-wheat cropping system of Punjab Province of Pakistan. Pak. J. Biol. Sci., 6: 1-6.

Kaundal, R., A.S. Kapoor and G.P. Raghava, 2006. Machine learning techniques in disease forecasting: A case study on rice blast prediction. BMC. Bioinf., 7: 1-16.

Kim, C.H., D.R. Mackenzie and M.C. Rush, 1987. A model to forecast rice blast disease based on weather indexing. Korean J. Plant Pathol., 3: 210-216.

Kim, K.H., J. Cho, Y.H. Lee and W.S. Lee, 2015. Predicting potential epidemics of rice leaf blast and sheath blight in South Korea under the RCP 4.5 and RCP 8.5 climate change scenarios using a rice disease epidemiology model, EPIRICE. Agric. For. Meteorol., 203: 191-207.

Kumar, A., L. Willocquet, S. Savary and U.S. Singh, 1998. Soil-borne and Seed-borne pathogens of rice in Rice-wheat System-based farmers' fields in Uttar Pradesh. Intl. Rice Res. Notes, 23: 24-25.

Luo, Y., P.S. Teng, N.G. Fabellar and D.O. TeBeest, 1997. A Rice-leaf blast combined model for simulation of epidemics and yield loss. Agric. Syst., 53: 27-39.

Luo, Y., P.S. Teng, N.G. Fabellar and D.O. TeBeest, 1998. Risk analysis of yield losses caused by rice leaf blast associated with temperature changes above and below for five Asian countries. Agric., Ecosyst. Environ., 68: 197-205.

Mohapatra, N.K., A.K. Mukherjee, A.V.S. Rao and P. Nayak, 2008. Disease progress curves in the rice blast pathosystem compared with the logistic and gompertz models. J. Agric. Biol. Sci., 3: 28-37.

Ou, S.H., 1980. A look at worldwide rice blast disease control. Plant Dis., 64: 439-445.

Prabhu, A.S., C.S. Silva and M.C. Filippi, 2008. The Potential Impact of Climate Change on Rice Diseases in Brazil. In: Climate Change: Impacts on Plant Diseases in Brazil, Ghini, R. and E. Hamada (Eds.). Embrapa Meio Ambiente, Brazil, pp: 140-158. 
Rossman, A.Y., R.J. Howard and B. Valent, 1990. Pyricularia grisea, the correct name for the rice blast disease fungus. Mycologia, 82: 509-512.

Saka, N., 2006. A rice (Oryza sativaL.) breeding for field resistance to blast disease (Pyricularia oryzae) in Mountainous Region Agricultural Research Institute, Aichi Agricultural Research Center of Japan. Plant Prod. Sci., 9: 3-9.
Savary, S., A. Nelson, L. Willocquet, I. Pangga and J. Aunario, 2012. Modeling and mapping potential epidemics of rice diseases globally. Crop Prot., 34 : 6-17.

Teng, P.S. and J.E. Yuen, 1991. Epidemic Models: Lessons from Plant Pathology. In: Risk Assessment in Genetic Engineering, Levin, M.A. and H.S. Strauss (Eds.). McGraw-Hill, New York, USA., pp: 272-296. 